\title{
Application of Building Information Modeling (BIM) technology in the quality management of prefabricated buildings
}

\author{
Cong Peng ${ }^{1}$, Xing $\mathrm{Li}^{2}$ ** \\ ${ }^{1}$ Department of Civil Engineering, Guangxi Vocational College of Water Resource and Electric Power, City of Nanning, China \\ ${ }^{2}$ Chengxin Group Corporation Limited. City of Nanning, China
}

\begin{abstract}
Recent years, China is focus on promoting prefabricated buildings in the field of construction and increasing the assembly rate of various buildings throughout the country, and it should pay more attention to the quality issues of prefabricated construction. BIM technology is a emerging science and technology, it has the advantages to control the quality of the construction, and play the critical role in the production and construction of prefabricated buildings. The application ideas of BIM technology and put forward, which provide a reference for improving the quality of prefabricated buildings.
\end{abstract}

\section{Introduction}

At present, in China's construction engineering market, the pilot construction of prefabricated buildings has been gradually carried out, and under the encouragement of national policies and local documents, the application and assembly rate of prefabricated buildings are also increasing year by year. According to the national strategic layout of construction industry, prefabricated building will become the main form of construction products in the future, which will provide new building forms for industrial transformation, low-carbon construction and sustainable development of buildings. Therefore, the quality of prefabricated building should be pay more attention to, and BIM technology is helpful to prefabricated building quality management.

\section{Application of BIM Technology in production quality management of prefabricated building components}

\subsection{Application of BIM Technology in quality management of standardized component manufacturing}

Compared with the traditional construction and production mode, the primary production link of prefabricated building is carried out in the factory. In order to ensure that the prefabricated components produced by the factory meet the quality requirements, quality management should be carried out from the source, that is, quality control should be carried out from the design stage. The traditional design scheme is mainly presented in twodimensional drawing mode, while the main feature of BIM Technology is that visualization and information parameters are displayed in 3D components, which is convenient for accurate design of components and avoid design errors. At the same time, according to the relevant specifications, standards and other requirements, reasonable lifting points should be set in the prefabricated components to facilitate the on-site hoisting construction of the later components. In the design of the lifting point position, a collision check should be paid attention to avoid the conflict between lifting point and reserved hole[1].

\subsection{Application of BIM technology in PC component transportation quality management}

BIM technology, as a new means of information technology, exerts a vital influence in the transportation stage, which can carry out dynamic management of component information, code and identify parameters such as category, size, location and quantity for each component from early design, and combine coding with RFID technology to realize dynamic management of component production and transportation[2]. BIM integrated management platform can be used to share component information, and all relevant personnel can access the immediate production and location of components according to their authority, and use BIM technology to carry out 3D mode transportation environment to avoid transportation In addition, management software and plug-ins for transportation planning can be developed based on BIM technology, and a transportation moving line model can be established between the production address and the construction address, and the problems of transportation trips, routes, transportation vehicles and vehicle selection can be analyzed to provide data reference for resource allocation.

\footnotetext{
Xing Li: shinelixing@hotmail.com
} 


\section{Application of BIM technology in quality management of prefabricated building construction process}

\subsection{Application of BIM technology in quality management during hoisting}

The biggest difference between prefabricated buildings and traditional buildings lies in the main work content of the construction site. Traditional buildings mainly use cast-in-place concrete structures to construct concrete structures, while the construction sites of prefabricated buildings mainly use hoisting techniques. According to the deployment of the design drawings and construction plan, the components are hoisted to the designated location for on-site installation or connection. Therefore, in the construction process, hoisting work has an indispensable impact on the quality of the prefabricated building.

After using BIM technology and RFID technology in the preliminary design, component production, transportation, and storage, the components have unique codes, and the classification and positioning are relatively accurate, which is convenient for hoisting work. Between hoisting, the construction plan can be simulated through the BIM building model, and the construction process can be fully embodied in three-dimensional form, which is convenient for technicians and operators to carry out actual operations, and can also achieve the role of visualization technology.

\subsection{Application of BIM technology in quality management during node processing}

In prefabricated buildings, most of the components are prefabricated and hoisted on-site, so there will be a large number of construction node work to be completed on the construction site, especially for complex prefabricated buildings, the treatment of nodes is particularly important, and the overall construction Quality also plays a key role, so project technical management personnel should pay attention to the handling of construction nodes[3].

For example, for the assembled steel structure type of building, we can use Tekla software of BIM technology system to analyze the complex steel structure joints, and calculate and simulate the stress state of the joints, so as to make a scientific and reasonable construction plan. For the reinforced concrete type of prefabricated building, it is necessary to carry out the force analysis of the reinforcement and the concrete parts simultaneously, and calculate the engineering quantity, taking into account the safety, aesthetics and construction Operability, the construction program is adopted in accordance with the characteristics of the project nodes. At present, we have the series of software are developed on the basis of Revit software platform in our country can be used to simulate and analyze this process, and can achieve certain precision and assist the construction plan.

In addition, it is worth noting that due to a large number of field lifting work needs to be combined with the field joint connection, so the accuracy requirements for the lifting and joint connection departments are relatively high, and excessive deviation can not occur, otherwise, it will cause great difficulty for the construction assembly and affect the overall quality of the project construction.

\subsection{Comprehensive Application of BIM technology in construction quality management}

In order to achieve the goal of whole process management and QC management of prefabricated building construction, BIM technology can be integrated from the early stage of construction to the design stage. Make a list to contain all the components of the information data, and demonstrate the quality requirements, as a quality management basis for the late construction. Secondly, the BIM model can be used to simulate and analyze the parts and construction process that are difficult to show and identify on some 2D drawings, and clear the relevant technical personnel, management personnel of the quality management.

Then BIM technology can be combined with secondary development, combined with construction management, to achieve 5D management, provide model data basis for construction quality management, ahead of time to do quality control key analysis, combined with onsite construction, focus on key parts of the key process control, also facilitate the quality inspection personnel according to the model information for the focus of inspection, to ensure project quality.

Besides above, the BIM technology can also provide management assistance for prefabricated building project management, through the division of quality responsibility, the establishment and continuous improvement of quality management organizational structure, to determine the job responsibilities of all staff, provide information data for QC team, and also provide data support for quality process information tracing, positioning, construction rectification and so on. At the same time, BIM can also be combined with IFC standards to build enterprise standards, for the long-term quality stability of enterprises to provide a scientific guarantee.

\section{Empirical application of BIM technology in construction quality management of prefabricated buildings}

\subsection{Project brief}

The project is located in the South New District of Chongzuo City, Guangxi Zhuang Autonomous Region, adjacent to the new sports center of Chongzuo City in the west, ASEAN Avenue in the north and Jinlong Lake Park in the south. In order to promote the transformation and development of investment promotion and accelerate the implementation of investment promotion, Chongzuo City has promoted the first Vientiane gathering project in Guangxi, Chongzuo Chengnan District commercial complex project. As a commercial shopping center, the design of the project considers the combination of "flowing" and "layer by layer" with the urban 
characteristics of "nature", "nationality" and "border trade". The building area is about 87000 square meters, with 1 floor underground and 3 floors above ground, with a height of 18 meters. After completion, it will become the commercial image symbol of Chongzuo city.

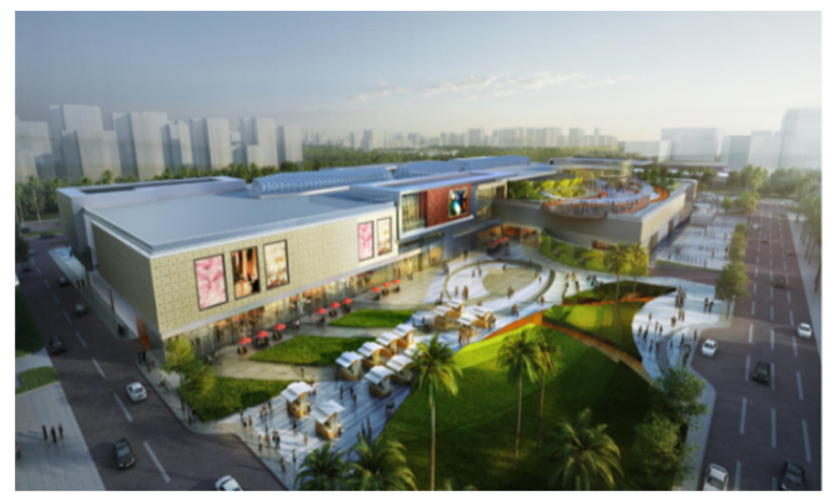

Fig. 1. Renderings of commercial complex project in Chengnan District, Chongzuo, Guangxi, China

In this project, BIM technology was used to design prefabricated components, and the construction unit was cooperated to preview the hoisting of prefabricated components in advance, which simulated the site to the greatest extent and achieved good results. The core of prefabricated buildings is prefabricated components. Whether the prefabricated components can be directly assembled as planned during the construction phase depends on the design quality of the prefabricated components. Therefore, the design phase of prefabricated buildings is very critical. The design process of prefabricated components involves the coordination of multiple roles. Compared with general buildings, it requires higher accuracy and timeliness of information transmission.

The entire BIM design process is divided into four stages: schematic design, preliminary design, construction drawing design, and component deepening design. The prefabricated component design is in two stages: preliminary design and component deepening design. The appearance and function design of the component is the basis of the preliminary design. Reasonable selection of component types and sizes will greatly increase the batch size of components, improve efficiency, and reflect the advantages of industrial production.

\subsection{Application of innovative BIM technology in the design stage}

At the same time, in the practical application of BIM technology of the project, there is a more innovative modeling method, which uses real-world modeling + BIM modeling to construct the project information model, which better restores the design concept and breaks the design and reality. Barriers to the construction effect.

Real scene modeling is to analyze the static objects of several photos taken from different viewpoints, and automatically detect the pixels corresponding to the same physical point, and automatically generate high resolution through continuous shooting and $70 \%$ overlap rate of adjacent two photos Resolution 3D model. The advantages of real-world modeling have many advantages in practical applications: it is not limited by the shape of the model, the generated model is more realistic, the model generation speed is fast, and the design time is saved.

The main differences between BIM modeling and realworld modeling are as follows: (1) The BIM model does not look real; (2) It is difficult to model things with irregular shapes. Real scene modeling is almost not limited by shape; (3) Different types of BIM models need different software, but different types of real scene modeling require only one software, ContextCapture (CC for short). (4) BIM modeling is difficult to build largescale models in a short time, for example, city modeling. (5) The size of the BIM model is input, and the size of the real scene modeling is given by the model.

As construction projects are often unable to take into account all the buildings and things around the project construction, the designed effect cannot be demonstrated in the real scene, resulting in unsatisfactory effects. Through context capture real scene modeling and model post-processing software, the real scene model can be combined with the BIM model, which can achieve the effect of animation demonstration, so that the unreal BIM model and the real scene model scene can be perfectly integrated.

\subsection{Application of BIM Technology in the construction stage}

The project adopts an integrated ground system, integrated wall and other types of integrated construction schemes. For prefabricated buildings, its core is "integration", and the BIM method is the main line of "integration". This mainline connects the whole process of design, production, construction, decoration and management, serving the whole life cycle of design, construction, operation and maintenance and demolition. It can describe various system elements by digital virtual and information technology, and realize the new application of informatization collaborative design, visual assembly, engineering quantity information interaction, node connection simulation and inspection, and integrates the whole construction industry chain, realizes the whole process and all-round information integration. The core of BIM Technology is information sharing and collaborative work. As the mainline of Architectural "integration", it can connect all aspects of design, production, assembly, decoration and management in the whole life cycle of architecture to form the whole industrial chain, whole process and all-round information integration.

In the whole process of project construction, the main structure system, peripheral protection system, electromechanical equipment system and decoration system are assembled through overall technical optimization, multi-discipline collaboration and according to certain technical interface and collaborative principle. This integrated construction method coincides with the idea of the collaborative sharing of BIM technology. Both of them share and integrate each link of each system 
through collaborative technology to form an integrated thinking and management mode, and the concept of integrated collaborative management is the same as that of organization and integration in EPC general contracting. The overall prefabrication rate of the project reached $51 \%$, and the assembly rate reached $61 \%$. Because the project adopts a steel-concrete composite structure, and uses a series of new building materials and prefabricated parts; therefore, in the project management of the construction process, innovative project management methods, digital information management, and the use of advanced BIM, VR, 3D measuring instruments, etc. Technology and equipment, realize the refined management of the project, and ensure the realization of the new construction method and new technology. In terms of dust, noise, wastewater and construction waste, pollution has been reduced by more than $50 \%$, which has huge social benefits.

\section{Conclusion}

With the continuous development of prefabricated buildings in various places, the quality requirements for prefabricated buildings will become higher and higher. For construction units, improving project quality, improving production efficiency, and reducing production costs are the main goals of construction management. Therefore, they should continue to explore the integration of advanced technologies, such as the combination with BIM technology, to provide information management for project management.. And BIM technology will resolve the contradiction between the practice of prefabricated building and traditional project management methods, and to promote the transformation of the construction industry, sustainable development of prefabricated building.

\section{Acknowledgments}

The authors acknowledge the financial support from the 2018 Guangxi's middle-aged teachers 'basic ability improvement project: Application and Practice of BIM in Information Treatment of Quality Control in Assembly Construction (2018KY1010) /Application and Research of DMBP Intelligent Building Technology In Guangxi (2021KY1098).

\section{References}

1. Jin Huiwen, Zhou Jiwei, Yi Xipeng. Research on the application of BIM Technology in the quality management of prefabricated building construction. Civil engineering graphics branch of China graphics society. The 7th BIM Technology International Exchange Conference: intelligent construction and building industrialization innovation and development. /Civil engineering graphics branch of China graphics Society: Editorial Department of civil construction engineering information technology, 2020:3

2. Cheng Xuewei. Research on the problems and optimization measures of the production and construction quality of prefabricated buildings. Ceramics, 2020(08): 128-129.

3. Zhou Haiyan. Design and application of prefabricated structure in a multi-storey commercial. China Metallurgical Construction Research Institute Co., Ltd. Proceedings of the 2020 Industrial Building Academic Exchange Conference (Volume 2). /Building Research Institute Co., Ltd.: Industrial Construction Magazine, 2020: 4. 